\title{
Job Satisfaction of Women Working in Johannesburg Skincare Clinics
}

\author{
Malebo K. Makhuza ${ }^{1}$, Karien Henrico K. ${ }^{1} \&$ Elsabe W. Nel ${ }^{1}$ \\ ${ }^{1}$ Faculty of Health Sciences, University of Johannesburg, Johannesburg, South Africa \\ Correspondence: Karien Henrico, Faculty of Health Sciences, Johannesburg, Gauteng, South Africa. Tel: \\ 27-11-559-6464. E-mail: karienr@uj.ac.za
}

Received: July 4, 2018 Accepted: July 30, 2018 Online Published: September 3, 2018

doi:10.5539/gjhs.v10n10p11 URL: https://doi.org/10.5539/gjhs.v10n10p11

\begin{abstract}
Women who work in skincare clinics have demanding jobs. Literature indicates that these working environments are labour intensive and emotionally demanding. The aim of this study was to explore and describe the perceptions of job-satisfaction factors for women working in skincare clinics in the northern suburbs of Johannesburg, South Africa. In this study, individual semi-structured interviews, based on the philosophy of Appreciative Inquiry, were conducted. Data was analysed through thematic coding and strict ethical considerations and trustworthiness were adhered to. From the identified themes, eleven recommendations were derived aimed at improving the job-satisfaction of women working in skincare clinics.
\end{abstract}

Keywords: appreciative inquiry, job satisfaction, qualitative, somatology, therapists

\section{Introduction}

The skincare industry has been described as being labour intensive and emotionally draining by various authors (Linnan, D'Angelo, \& Harrington 2014; Henrico, 2015), it is also seen as a vocational domain. Women who work in these skin care clinics (known as a somatologist in South Africa), relies on adequately managing human resources, as they work with clients on a daily basis and administer treatments that focus both on cosmetic and holistic outcomes. Henrico (2015) stated that skincare clinics are often dominated by female employees and owners and these clinics are seen as small businesses, as they often employ between 1-19 employees per establishment (Barnes Report, 2012). Such small, privately owned businesses often do not focus on the job-satisfaction of employees or therapist, in this instance (as seen in larger companies), because of the lack of resources, such as staffing and financial resources (Neely, 2012). Job satisfaction pertains to any industry where human resources are involved. Therefore the aim of this study was to explore and describe the perceptions of job satisfaction factors for women working in skincare clinics.

In improving job satisfaction for women working in skin care clinics, it became evident that the main themes were primarily concerned with the external and internal motivational perception factors, the ideal work environment and the dream to enhance and facilitate job satisfaction for these women.

In many instances, the clientele that skincare clinics serve are women. The types of treatments performed on clients include grooming treatments such as waxing, laser hair removal, facials, manicures and pedicures as well as holistic treatments such as aromatherapy massage and reflexology to name a few (Straughan, 2010). These treatments can be quite labour-some in practice and may also be emotionally demanding as per each individual client's needs which the therapist aspires to tend to in order to ensure that the client leaves the clinic feeling satisfied with the service that was rendered. This leads to one questioning what the perceptions of factors are that warrant a therapist to stay in their position as a therapist in a profession that is as physically and emotionally demanding.

\section{Research Method}

A qualitative, descriptive, exploratory and contextual design was used in conducting this study (Isaacs, 2014). The qualitative nature of this study enabled the researcher to explore and describe the perceptions of women who work in skincare clinics. Isaacs (2014) explained that this approach assists one in exploring social and behavioural issues, which would not be as thoroughly explored by a quantitative research method. According to Dumay and Qu (2011), qualitative research is specific to research where the researcher aims to explore and understand a participant, more so where their experiences and perceptions will be probed. 
Qualitative research is a methodology that allows one to probe and explore a participant's view so as to understand the perspective or point of view (Dumay \& Qu, 2011). The characteristics of qualitative research include flexibility, the ability to be fluid as well as the ability to immerse oneself in data and literature that relates to exploring the experiences of somatologists (Isaacs, 2014).

\subsection{Population and Sampling}

Purposive sampling was used in study (Robinson, 2014). The target population consisted of women working in skincare clinics in the northern suburbs of Johannesburg, South Africa. The sample size was ten $(n=10)$ were after data saturation occurred. The selection criteria used for this study were, women who:

- worked in salons situated in Rosebank and/or Fourways, South Africa during the data collection phase of this study,

- have been working in the industry for one year or longer,

- holds a national diploma or equivalent somatology qualification,

- speak English, and

- all ages were included,

It is assumed that the potential participants who comply with the inclusion criteria, as stipulated above will be able to assist the research team in collecting information rich data. Individuals who did not adhere to the criteria of this study, was not included in this study. Participants in this study were all full time skincare clinic employees, and aged between $20-40$ years of age.

\subsection{Data Collection}

The study was conducted in the northern suburbs of Johannesburg, South Africa (June-October 2017). A pilot study was conducted on a small sample before the remainder of the participants were interviewed. The data for this study was collected by means of in-depth, individual semi-structured interviews, field notes and a reflective diary.

The philosophy of Appreciative Inquiry (Cooperrider, 2013) informed this study, and was applied when developing the interview questions and conducting the in-depth, individual, semi-structured interviews used as main data collection tool. The questions asked were as follows:

1) How would you describe your most memorable work experience?

(Discovery)

2) What would your ideal work environment consist of?

(Dream)

3) What would you add to your work environment in order to ensure your job satisfaction?

(Design)

4) How would you implement such changes?

(Delivery)

According to Creswell (2017), these interviews are recorded as a guided conversation between interviewer and interviewee where the interviewer has prepared questions to ask the interviewee in order to yield a positive result in terms of collecting data.

In order to achieve this, the interviewer obtained signed consent from the participant and the salon management if the interview was to be conducted on the premises of the somatology clinic. The interviewer arrived $15 \mathrm{~min}$ early for the interview in order to prepare for the various interviews, prepare the recording devices as well as find a suitable location for the interviews.

Field Notes were collected to add to the context of the study. These notes were in the form of side notes made from the researcher's experience and observations and were written down as per the researcher's impression (Greener \& Martelli, 2015). The researcher's thoughts, feelings and observations were noted after each interviews, so as to add to the context of what had been discussed in each of the interviews and keeping in mind the setting (Greener \& Martelli, 2015). The interviewer made the field notes, after each interview to note down any significant observations or data that was noted in the interviews.

The reflective process of the researcher is integral to the facilitation of the qualitative research as a methodology (Walker, Read, \& Priest, 2013). This was achieved by means of a reflective diary kept for the duration of the 
research. This assisted the researcher in keeping clear thoughts and ideas and to enhance trustworthiness. It also assisted in providing a tool which is used to highlight the ways in which one could maintain transparency during the study to make explicit any bias that the researcher has towards the participant and the study, as well as to give further background that will help in triangulation when data analysis is conducted.

After achieving data saturation, the interviews were then transcribed, coded and analysed in order to develop the guidelines presented in the study.

\subsection{Data Analysis}

Data analysis is how the collected data is processed and analysed in order to give meaning to the collected data from observation and the primary data that was collected during the interviewing of participants (Greener \& Martelli, 2015). Thematic coding was used as the data analysis strategy after the interviews were transcribed verbatim.

From coding, units of meaning is developed from the data (Greener \& Martelli, 2015). The aim here is identify the perception of factors or aspects which will answer the research question and the interpretation thereof. At first, summaries were made of each interview where the most important points were highlighted. Here, code words were derived and each of them noted down for each participant. This allowed the researcher to deduce what presented itself most frequently and pertinently from the data collected.

An independent coder with vast experience in qualitative data analysis, was brought in to assist in this process of coding. A consensus discussion was held between the researcher and the independent coder. Identified themes and sub-themes that were then integrated with the codes derived by the researcher. These were then used at a later stage to develop the 11 guidelines and a description of the application thereof. These guidelines addressed the concerns of women working in skincare clinics as well as identifying various perceptions of job satisfaction factors.

\section{Ethical Considerations}

Ethics are good ideologies and ideals that guide activities. Such principals are frequently enshrined in codes of conduct developed for specific settings and professions, such as the four principals of "... respect, competence, responsibility and integrity..." (Thompson \& Russo, 2012). Some of the rights which were adhered to in this study include the right to confidentiality, the right to fair treatment, the right to an informed consent, impartiality, the right to no physical and psychological harm as well as the right to dignity (Rammanhor, 2015:62). The ethical approval to conduct this study was obtained from the ethics committee before the field work was conducted for the data collection phase of the study so as to ensure that no harm would come to the participants. Part of observing ethical considerations in the study was done through ensuring that the data collected was securely stored and that access to the data and the information of the participants was restricted.

\section{Trustworthiness}

Trustworthiness refers to the ability of the researcher and the processes followed by the researcher to be trustworthy. This includes looking at the study's credibility, transferability, confirmability and dependability. Bracketing and a reflective diary was used to ensure that the areas where bias occurs are clearly marked and with reason, to keep the findings and outcomes of the study unadulterated, adding to the credibility and validity of the data (Chan, Fung, \& Chien, 2013).

According to Maaloe (2015), the study should be able to yield similar results should another researcher take on the same study as a display of reliability and transferability. In this study, the findings are limited to somatologists working in skincare clinics in the northern suburbs of Johannesburg, South Africa. However thorough description of the research methods will allow another study to be conducted in a different contextual setting.

\subsection{Dependability}

The dependability of the study is ensured through the detailing of procedures undertaken in data collection, data analysis and in the presentation of data (Maaloe, 2015). This is a process that requires for one to pull from all processes involved in the data collected, including the field notes and the reflective diary. According to Maaloe (2015:74), the researcher needs to be relentless in the pursuit of clearly stating what it is that is meant to be realised in the study and by stating how the findings are to be realised. This was achieved through shedding light on how the reflective diary and field notes were used along with an example of what was documented in each resource.

\section{Findings and Discussion}

Through having conducted the study, themes and sub-themes were developed (as per data analysis) so as to single out the perceptions of factors that improve job satisfaction amongst women working in skincare clinics. Table 1 
summarises the units of meaning that were identified from the data analysis of this study.

Table 1. Perception of factors that improve job satisfaction amongst women working in skincare clinics

\begin{tabular}{|c|c|}
\hline THEMES & THEME \\
\hline $\begin{array}{l}\text { 1. External Motivational Factors are that the environment lends } \\
\text { itself to the development of self-confidence and self-esteem }\end{array}$ & $\begin{array}{ll}\text { - } & \text { Positive practice environment } \\
\text { - } & \text { Harmony within the environment } \\
\text { - } & \text { Clients }\end{array}$ \\
\hline $\begin{array}{l}\text { 2. The ideal work environment lends itself to the internal factors } \\
\text { for Job Satisfaction. }\end{array}$ & 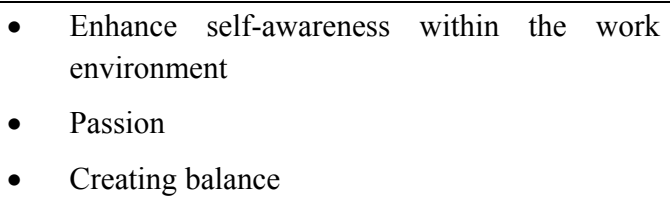 \\
\hline 3. Dreams to enhance job satisfaction & 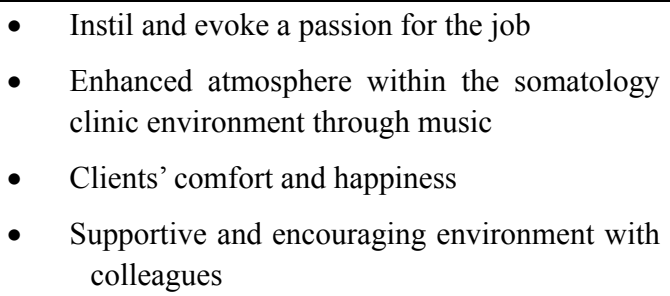 \\
\hline
\end{tabular}

As seen in the discussion to follow, the perceptions of factors that arose from the responses of the participants reflect and lean heavily towards having a passion for the industry and the treatments that yield results for the clients that the somatologists work on. Other factors that have been discussed include a passion to achieve client satisfaction and the importance of having and maintaining a positive work environment, fostering positive relationships with fellow somatologists/peers and with the management of the somatology clinic.

\subsection{External Motivational Factors}

Job satisfaction is perceived by participants in this study as being related factors that keep these women in their job and ultimately satisfied and motivated. According to Singh (2016), motivation is seen as the drive, strength and essentially the energy that pushes an individual to stay focus and engaged in a certain activity or task that they are doing. Motivation can be drawn from the fulfilment that one receives from their work, their personal drive to improve themselves and it can also depend on one's environment and surroundings (Singh, 2016:30-31). Understanding what motivates an individual may assist with identifying ways to keep employees motivated and engaged in their work as well as in fostering the perception of job satisfaction. This is elaborated on by focussing on the factors that pertain to the environment these women would work in. These factors highlighted were a positive practice environment, harmony within the environment and the clients.

"As long as my guests are happy and then we have a good team, that's perfect...Most clients are happy because of the service and the results... if you don't have good products and good equipment's, you don't get good results." P6.

The above-mentioned participant highlights the importance of exhibiting client care, a genuine interest in the client's well-being as well as the influence that the environment and setting has on how women working in skin clinics are able to take care of the client appropriately. This participant's experience and perception highlights the significant role that one's environment plays in the passion and relationship that one has for their clients, their work, their enthusiasm and their perception of job satisfaction as a whole.

\subsection{Internal Factors for Job Satisfaction}

The ideal work environment lends itself to the perceptions of internal factors for job satisfaction. According to Ealias and George (2014:1), job satisfaction refers to the pleasant and positive attitude or emotional perception that one has towards their job or work. Job satisfaction is said to occur when all employee needs and wants are met, together with the individual's work values being realised and fulfilled. Ealias and George (2014:1) support the notion that a significant role that the internal environment of an organisation plays in the job satisfaction of employees of the respective organisation needs to be brought to the attention of somatology clinic management. 
“It's everything, like in a somatology clinic how you wanna use the five senses of almost, to say, there's different aspects a happy environment, it's the people you work with, it's from management to your co-workers to the clients... Okay, management, you need a good management. They need to understand you. You need to feel like they looking out for you. I don't want to say like, not like abuse you know.” P9.

It is important to note that managers need to factor this into their management strategies when working with not only women in somatology clinics, but in managing the environment as a whole, where the environment and atmosphere lends itself the success of treatments and the success of the somatology clinic in acquiring repeat customers. The perceptions of factors which were brought to light included enhancing self-awareness within the work environment, passion and creating balance.

\subsection{Dreams to Enhance Job Satisfaction for Somatologists}

Ealias and George (2014:1) mentioned that job satisfaction is when one has reached and managed to maintain a positive emotional state towards their work place as it is perceived by the individual, when their needs have been met by the respective organisation or the work environment. The section below delves into how the somatology clinic management can be better able to enhance and evoke the passion that the somatologist started with when they entered the work environment. This would benefit not just those newly qualified somatologists, but those who have been working in the industry for a few years through highlighting a few perceptions factors such as instilling and evoking a passion for the job as a somatologist, enhancing the atmosphere within the somatology clinic as well as the comfort and happiness of clients.

"...We actually have to have a passion. I find that these days a lot of somatologists come in this industry because they just could not do anything else.” P2.

Another participant went on to say the following:

“I am very passionate about beauty. It is my calling...For real, its passion that is keeping you there.” P2.

This quote gives insight into the participant's opinion and observation that is in essence, the crux of the reasons why women stay in their positions within these skincare clinics. Passion as a determinant is highlighted here as having a great influence on the job satisfaction of women playing.

\section{Job Satisfaction Recommendations and Implications}

The recommendations below have been taken from the findings of the study so as to highlight the practical application(s) of each recommendation as per the participants of the study. This is with the aim of improving the perception of job satisfaction factors of therapists working within the somatology clinics thus addressing the issue of high staff turnover within the somatology clinic environment(s) and finding out reasons why therapists stay in their respective roles within the somatology clinics. Below are the recommendations that were developed in the study from the data collection and literature.

\subsection{Developing Self-Esteem and Self-Confidence}

\subsubsection{Attending Regular Training and Development}

Regular training and development for newly appointed and previously appointed women should result in them gaining experience and being well versed in new developments within the skincare industry. Training and development should include an orientation programme (Tabassi, Ramli, \& Baker, 2012:3; 2016:83). The implication of this will be in staff that is highly motivated and well skilled to carry out their tasks optimally.

\subsubsection{Creating Self-Awareness Amongst Women Working in Skincare Clinics}

Developing self-esteem and self-confidence in women working in skincare clinics should result in a keen sense of mindfulness, introspection and thus positively impact one's performance and capabilities in the workplace (Ferris et al., 2015:279). Sufficient training and development should result in gaining competence in a skill (Chieochankitkan, 2013:1) which should also result in a greater sense of self-awareness. Allowing women to fulfil more roles than just that presented in their capacity as a skincare therapist should increase one's self-esteem (Ferris et al., 2015:279). Creating and fostering a sense of self-awareness within a therapists results in an individual being confident enough to carry out their work optimally and thus develops a sense of responsibility and ownership towards themselves and their work.

\subsection{Enhancement of Internal Job Satisfaction Factors}

\subsubsection{Establishing a Rapport With Clients}

Facilitating a good rapport between women working in skincare clinics and clients should result in these women 
having a recurring client, which should act as a form of appraisal and indicates an appreciation for excellent service (Chen, 2014). Having clients who are happy with your service and the rapport developed with them fuels the passion one has for their job in the somatology clinic (Chieochankitkan, 2013). Implementing customer feedback mechanisms will assist women working in skincare clinics in receiving feedback from clients (Chen, 2014).

The above-mentioned points indicate the importance of exhibiting client care, a genuine interest in the client's well-being as well as the influence that the environment and setting has on how one, as a skincare therapist, is able to take care of the client appropriately. This is essential as it can either make or break a therapist's credibility and may have an impact on the therapist's remuneration.

\subsubsection{Facilitating Passion}

Nurturing passion for the skincare industry by not allowing women to burnout facilitates and enhances their passion for the somatology profession and their workplace, allowing to perform optimally with energy and vigour (Chen, 2014) as achieved through allowing adequate down time and creating a balance in their professional and private lives. Access to products and resources that allow for skincare therapists to see results in the treatments and services they offer to clients should facilitate passion and enhance job satisfaction (Olamilekan \& Dastane, 2014).

These are important points to note as they refer to having the management of the establishment ensuring that the therapists are properly equipped to execute their duties to the best of their abilities. This is through ensuring that the necessary resources are available to the therapist in order to service the respective patron optimally.

\subsubsection{Creating a Harmonious Work Environment}

A harmonious work environment where one has career advancement opportunities, work at a pleasant pace and can meet the expectations of the employer should influence one's perception of job satisfaction in the somatology clinic positively and thus enhance one's internal job satisfaction factors (Ealias \& George, 2014). A harmonious work environment, where the relationship between a therapist and their colleagues as well as the management of the somatology clinic is positive, enhances the feeling of internal job satisfaction (Joshi, 2013) that is achieved through adequate performance appraisals and team effectiveness workshops.

Having a positive, tranquil and harmonious environment wherein women can acquire loyal clients and meet the relaxation needs of a client should result in a satisfied client, which in turn enhances the job satisfaction of the skincare therapist (Ealias \& George, 2014) as the challenges in the workplace are worked out amicably and effectively so that both parties are pleased with the outcome. The notion of creating a harmonious environment within the somatology clinic is essential as not only does it influence the therapist or their quality of work but it also influences the experience that is had by the client. Having clients that have pleasant experiences reflects positively on the therapists and would certainly influence the perception of job satisfaction.

\subsubsection{Facilitating Team Work}

Establishing an environment where team work is facilitated and where women working in skincare clinics can boost each other and motivate each other should enhance the internal job satisfaction factors of the therapist (Chen, 2014). Creating a team with individuals who are harmonious and get along together without causing conflict should enhance job satisfaction factors for women working in skincare clinics (Wright, 2013:13). Allowing women to interact freely and casually in and outside of the formal somatology clinic setting should encourage them to bond as a team and should as a result enhance the internal job satisfaction factors (Wright, 2013:97). Ensuring that women are able to interact with each other in a relaxed setting allows for them to tend to each other's emotional stressors and allows for them to support each other which should increase their internal job satisfaction factors (Wright, 2013:97).

In encouraging team work amongst therapists, one is able to ensure that the staff motivate each other and that they form one another's support systems. Encouraging such cultures within a business ensures that there is a tranquil and positive work environment not just for the therapists working there but for the clients that they will service as well.

\subsection{Ideal Facilitation and Enhancement of Job Satisfaction for Women Working in Skincare Clinics}

\subsubsection{Managing the Somatology Clinic and Its Resources}

The management of the skincare clinic should ensure a positive practice where there are adequate resources for therapists to perform their tasks optimally such as retailing products (Reuford \& Scott, 2015). Being able to meet the needs of the client through using the resources available to therapists should facilitate job satisfaction for women working in skincare clinics (Olamilekan \& Dastane, 2014). Also management should create a dialogue for satisfactory remuneration (Secara, 2014:318-319). Through managing the skincare clinic's resources (which 
includes the staff itself), the clinic would benefit by means of seeing an increase in turnover and a decrease in staff turnover.

\subsubsection{Creating a Desirable Work Environment}

The skincare clinic management should conduct regular engagement surveys with employees in order to ascertain how they can improve the various job satisfaction factors of the women working in their skincare clinics and to ascertain their level of engagement with their work (Reuford \& Scott, 2015:16). There needs to be flexible working hours as far as possible (Secara, 2014:318-319). The implication of creating a desirable work environment for the therapists would most noticeably be the longevity of the therapists who work at the somatology clinic. This in turn results in a culture of having a positive work force and in happy clients as they would always receive satisfactory service from the therapists.

\subsubsection{Establishing a Nurturing Work Environment}

Creating an environment where individuals can "grow and thrive" as emphasised by Reuford and Scott (2015:12), is an important factor to be noted and should enhance/ facilitate job satisfaction. Working in an environment where there is harmony between the women who work in skincare clinics and the clinic management as well as support from both the management and the therapist should result in a nurturing environment where one performs optimally. Management needs to take considerations brought in by employees into account when making decisions (Zhang et al., 2014:1315).

Establishing a nurturing work environment would result in therapists knowing that they are cared for as their development and well-being is being kept in mind at all times. This would make it easier for one to attract great staff should someone leave the establishment on their own accord which in turn would result in developing a culture of positivity within the work environment as well. This in turn would translate in less staff turnover and greater turnover for the establishment as well.

\subsubsection{Facilitating Interaction Between Staff and Clinic Management}

Establishing an open-door policy through engaging with skincare staff should enhance the job satisfaction, as staff will feel heard and that their perspective is acknowledged (Olimaken \& Dastane, 2014:1). Having meaningful and casual conversations between clinic management and staff should facilitate the interaction between staff and clinic management, where an open-door policy would become a possibility and the women working in skincare clinics may feel that they have the support of the somatology clinic management (Zhang et al., 2014:1315). Ensuring that communication channels between the therapist and management is always open and clear ensures that there are no unfortunate misunderstandings which would lead to tensions in the work environment.

\subsubsection{Establishing Work Life Balance and Boundaries}

Skincare clinic management should assist women who work in skincare clinics with maintaining a balance between work-life and a private down time, to allow for one to rest and recover in order to perform optimally, which should enhance job satisfaction factors for these women (Henrico, 2015:9). Managing the stressors that come with caring for others and allowing time for some debriefing should enhance the job satisfaction of women (Reuford \& Scott, 2015:38). Equipping women in skincare clinics through workshops on enhancing their comprehension and application of emotional competency towards clients and their colleagues in order to establish a work life balance should enhance job satisfaction factors (Olamilekan \& Dastane, 2014:1).

In establishing a good work life balance for the therapist(s), one will find that the therapists are less likely to burn out and that they will be able to remain consistent in their performance. This should in turn result in a happier and more productive team of therapists which benefits both the establishment and the individual therapist.

\section{Conclusion, Limitations and Future Research}

This study highlights the perceptions of job satisfaction factors of women working in skincare clinics in the north of Johannesburg. The qualitative nature of the study has facilitated the development of guidelines which can be used practically in the field of somatology and other similar industries.

It is to this end that one needs to acknowledge that the relationship between the individual and their counterparts as well as the relationship between the employee and management of the skincare clinic at which one is employed play a major role in the perception of job satisfaction. It seems as if the biggest factor/determinant of job satisfaction for women working in skincare clinics relates to the relationships that they develop in the work place. The more positive the relationship, the more loyal the employee is towards the place of employment and their colleagues, which is what adds to one wanting to become rooted at the skincare clinic at which they are employed. It is these relationships that need to be managed delicately in order to achieve a good work-life balance, as this is 
one of the biggest perceptions of the factors that would improve job satisfaction for women working in skincare clinics in the northern suburbs of Johannesburg.

As a result, it can be concluded that the perception of having a sense of career satisfaction is influenced by various perceptions of factors. Such factor perceptions include remuneration, compensated, career advancement, skills development, creating good relationships amongst colleagues and reaching personal goals. When employees felt that their supervisors were satisfied with them, they felt a sense of emotional attachment with the organisation they were working at. It is vital that importance of workplace relationship are acknowledged, as this relationship plays a major role in the perception of job-satisfaction. This once again speaks to the notion that the perception of internal factors of job satisfaction are fostered through creating an ideal work environment which result in creating the sense of job satisfaction for the women working in somatology clinics.

Limitations of this study included the time consuming nature of the data collection. The interviewer noted that participants were conscious of the time which they had spent in the interview, in-case they would have to attend to a client. While conducting this research, it has become evident that there is still much to be researched in the somatology field as there is still room for more to be discovered relating to the industry from the perspective of a somatologist and what somatologists experience in their profession especially in relation to Human Resource Management topics.

\section{Competing Interests Statement}

The authors declare that there are no competing or potential conflicts of interest.

\section{References}

Barnes Report. (2012). The Barnes Report: U.S. beauty salons industry \& market report (NAICS 812112). USA: C. Barnes \& Co.

Chan, Z. C., Fung, Y. L., \& Chien, W. T. (2013). Bracketing in phenomenology: Only undertaken in the data collection and analysis process. The Qualitative Report, 18(30), 1-9.

Chiboiwa, M., Chipunza, C., \& Samuel, M. (2011). Evaluation of job satisfaction and organization citizenship behaviour: case study of selected organizations in Zimbabwe. African Journal of Business Management, 5(7), 2910-2918.

Chieochankitkan, A. (2013). Developing service quality for spa establishments in the active beach tourism cluster, Thailand.

Dartey-Baah, K., \& Harlley, A. (2010). Job Satisfaction and Motivation: Understanding its impact on employee commitment and organisational performance. Academic Leadership Journal, 8(4), p.39.

Dumay, J., \& Qu, S. (2011). The qualitative research interview. Qualitative Research in Accounting and Management, 8(3), 238-264. Emerald Group Publishing. https://doi.org/10.1108/11766091111162070

Ealias, A., \& George, J. (2014). Emotional intelligence and job satisfaction: a correlation study. The International Journals, 1(4).

Ferris, D. L., Lian, H., Brown, D. J., \& Morrison, R. (2015). Ostracism, self-esteem, and job performance: When do we self-verify and when do we self-enhance?. Academy of Management Journal, 58(1), pp.279-297. https://doi.org/10.5465/amj.2011.0347

Flick, U. (2015). Introducing research methodology: a beginner's guide to doing a research project (2nd ed.). Sage Publications.

Greener, S., \& Martelli, J. (2015). An introduction to business research methods. Bookboon.

Henrico, K. (2015). An appreciative self-management coaching programme to facilitate the wellness of somatology therapists (Doctoral dissertation, University of the Free State).

Isaacs. A. (2014). An overview of qualitative research methodology for public health researchers. International Journal of Medicine and Public Health, 318-319. Australia. https://doi.org/10.4103/2230-8598.144055

Kessler, E. (Ed). (2013). Appreciative Inquiry model: encyclopaedia of management theory. Sage Publications. https://doi.org/10.4135/9781452276090.n14

Linnan, L. A., D'Angelo, H. D., \& Harrington, C. B. (2014). A literature synthesis of health promotion research in salons and barbershops. American Journal of Preventative Medicine, 47(1), 77-85. https://doi.org/10.1016/j.amepre.2014.02.007 
Maaloe, E. (2015). Explanation and interpretation in social science: an integrated view with specific reference to case studies. Bookboon.

Neely, M. (2012). Wellness strategies for smaller businesses. Benefits Quarterly, 3rd quarter, 28(3), 16-19.

Olamilekan, O. A., \& Dastane, O. (2014). Employee Emotional Competency in Establishing Consumer Satisfaction and Loyalty: Mediate Role of Rapport in Malaysia Spa and Beauty industry. The International Journal of Accounting and Business Management, 2(1) 8-15. https://doi.org/10.2139/ssrn.2639670

Purdy, N. M. (2011). Effects of Work Environments on Nursing and Patient Outcome (PhD diss., University of Western Ontario).

Rademeyer, C. E. (2010). The knowledge, attitude and practice of health and skincare therapists at accredited clinics around South Africa with regard to nutrition (Doctoral dissertation, Stellenbosch: University of Stellenbosch).

Reuford, G., \& Scott, T. (2015). Human resources: a practical guide (1st ed.). Bookboon.

Robinson, O. C. (2014). Sampling in interview-based qualitative research: a theoretical and practical guide. Qualitative Research in Psychology, 11(1), 25-41. https://doi.org/10.1080/14780887.2013.801543

Secara, C. (2014). Job-between stability and satisfaction (pp. 318-319). Pitesi: Addleton Academic Publishers.

Singh, R. (2016). The impact of intrinsic and extrinsic motivators on employee engagement in information organizations. Journal of Education for Library and Information Science, 57(2), 197-200. https://doi.org/10.12783/issn.2328-2967/57/2/11

Straughan, E. (2010). The salon as clinic and problematizing, treating and caring for skin. Social and Cultural Geography, 11(7), 649-659. Routledge. https://doi.org/10.1080/14649365.2010.508563

Tabassi, A. A., Ramli, M., \& Bakar, A. H. A. (2012). Effects of training and motivation practices on teamwork improvement and task efficiency: The case of construction firms. International Journal of Project Management, 30(2), pp.213-224. https://doi.org/10.1016/j.ijproman.2011.05.009

Thompson, A., \& Russo, K. (2012). Ethical dilemmas for clinical psychologists in conducting qualitative research. UK: Routledge. p32-33.

Tracy, S. J. (2010). Qualitative quality: eight "big-tent" criteria for excellent qualitative research. Qualitative Inquiry, 16(10), 837-851. https://doi.org/10.1177/1077800410383121

Vallerand, R. J., Paquet, Y., Philippe, F. L., \& Charest, J. (2010). On the role of passion for work in burnout: A process model. Journal of personality, 78(1), pp.289-312. https://doi.org/10.1111/j.1467-6494.2009.00616.x

Wright, D. (2013). The myths and realities of teamwork (1st ed.). Bookboon.

Yeadon-Lee, T., Jewson, N., Felstead, A., Fuller, A., \& Unwin, L. (2011). Bringing on the customers: regulation, discretion and customer service narratives in up-market hair.

Zhang, X., Hu, B., \& Qiu, M. (2014). Job satisfaction as a mediator in the relationship between performance appraisal and voice behaviour. Social Behaviour and Personality, 1315. Republic of China.

\section{Copyrights}

Copyright for this article is retained by the author(s), with first publication rights granted to the journal.

This is an open-access article distributed under the terms and conditions of the Creative Commons Attribution license (http://creativecommons.org/licenses/by/4.0/). 